\title{
Physical and mathematical modeling of ignition of methane-air mixture in the presence of coal microparticles
}

\author{
Aleksandr Fedorov and Dmitry Tropin ${ }^{*}$ \\ Khristianovich Institute of Theoretical and Applied Mechanics SB RAS, 630090, 4/1 Institutskaya \\ Str., Novosibirsk, Russia
}

\begin{abstract}
The results of numerical investigation of the ignition of a stoichiometric methane-air mixture in the presence of carbon particles with diameters of $20-52 \mu \mathrm{m}$ in the temperature range $950-1150 \mathrm{~K}$ and pressures of 1.5-2.0 MPa are presented. The calculated data of the ignition delay times of coal particles in the coal particles/air mixture and of the ignition delay times of methane and coal particles in the methane/coal particles /air mixture are compared with the experimental ones. A satisfactory agreement of the data on the coal particles ignition delay times and methane ignition delay times in all the mixtures considered is shown.
\end{abstract}

\section{Introduction}

Investigation of the ignition and combustion of disperse systems consisting of a gas suspension of reactive particles in a mixture of gaseous fuels and oxidizer is relevant from the point of view of explosion and fire safety, for example in the coal mining industry. A vast experimental material on the ignition characteristics of single relatively large (with a radius of more than $20 \mu \mathrm{m}$ ) coal particles under conditions of weak convection of the oxidizing gas in the reaction chamber is contained in the monograph [1]. A lot of works are aimed at forecasting the conditions of ignition and flame propagation. The main attention was paid to the formation of a cloud of solid particles and initiation of its combustion due to local ignition and propagation of the combustion wave in methane. As shown in $[2,3]$, hybrid mixtures are more easily flammable than each of the components individually. A lot of work has been devoted to a theoretical study of the problem of ignition of coal suspensions (see [4-7] and references therein). The studies were carried out within the framework of point models of ignition of coal particles, the provisions of the Semenov's thermal explosion theory were widely used to formulate the critical ignition / extinction conditions.

Investigation of this phenomenon is also interesting from the point of view of controlling the process of ignition of the gas mixture, which can become the scientific basis for creating new combustion regimes for traditional fuels.

\footnotetext{
${ }^{*}$ Corresponding author: d.a.tropin@itam.nsc.ru
} 


\section{Physical and mathematical model}

Let us consider a space filled with the gas suspensions of coal microparticles with the diameters from 26 to 52 microns in air or in methane-air mixture, with high initial state parameters (temperature ranging from 850 to $1150 \mathrm{~K}$ and pressure ranging from 1.3 to 2.0 $\mathrm{MPa})$. We assume, as in $[5,6]$, that the processes of thermal destruction of coal particles occurs simultaneously with the release of volatiles into the gaseous phase, the ignition and combustion of volatiles in the gaseous phase, the heterogeneous reaction of oxidation of solid carbon (coke), the ignition and combustion of methane/air mixture. The mass rates of the pyrolysis reaction, oxidation reaction of solid carbon will be described in the form of diffusion-kinetic dependences presented in $[5,7]$. Kinetic constants for these dependences are presented in $[5,8]$. To describe the kinetics of ignition and combustion of gaseous volatile and methane/air mixtures we use the simplified detailed kinetic scheme [9]. Earlier, with the help of this kinetics model, we described the processes of propagation, attenuation and suppression of detonation in methane/oxygen and methane/hydrogen/oxygen mixtures [10], as well as the experimentally observed ignition delay times of gas suspension of iron particles in methane/air mixture [11].

\section{Calculation results}

The ignition of coal/air and methane/coal/air mixtures was calculated using the mathematical model [5-11]. As the particle ignition delay time we consider the time needed to reach the maximum particles temperature rise in time $-\max \left(\frac{d T_{2}}{d t}\right)$ follow [11-12].

\subsection{Coal particles/air mixture}

Fig. 1 shows the experimental [13] and calculated dependences of the ignition delay time of coal particles in air on the gas temperature at the end of the compression tact (the pressure at the end of the compression tact varies from 1.5 to $1.77 \mathrm{MPa}$ ). It is seen from fig. 1 that the increasing of the gas temperature results in decreasing the ignition delay time of the coal particles. In addition, in the whole pressure range $(p \in(1.5,1.77) \mathrm{MPa})$ and temperatures $(T \in(897,1123) \mathrm{K})$ of the mixture under consideration, we have a good agreement between the experimental and calculated values of the ignition delay of coal particles.

\subsection{Methane/coal particles /air mixture}

Fig. 2 shows the experimental [13] and calculated dependences of the coal particles ignition delay times and the methane ignition delay times in the methane/coal particles /air mixture on the temperature of the gas mixture at the end of the compression tact. It can be seen that there is a satisfactory agreement between the experimental [13] and calculated ignition delay times in all considered pressure ranges $(p \in(1.6,1.82) \mathrm{MPa})$ and temperatures ( $T \in(989,1052) \mathrm{K})$ of the mixture. 


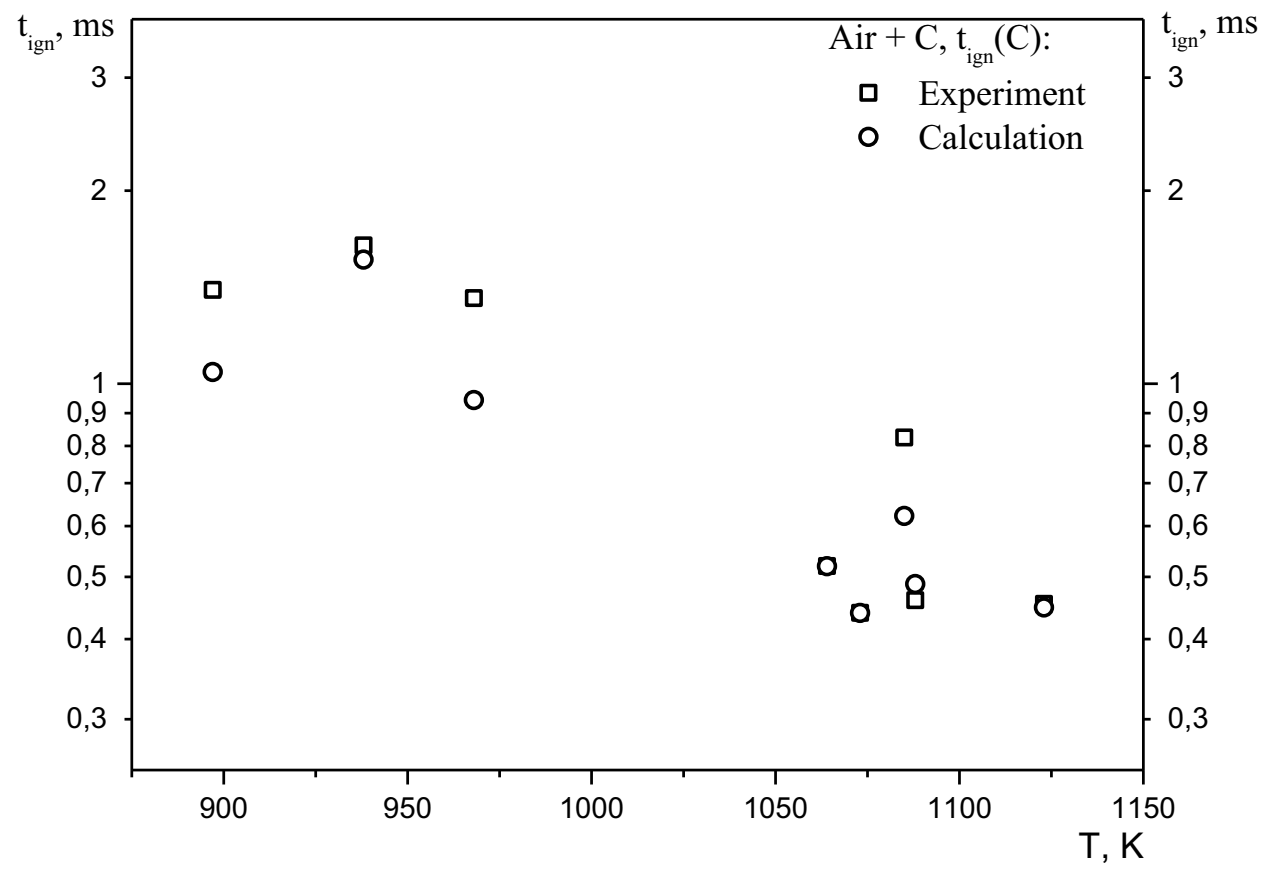

Fig. 1. Dependences of ignition delay time of coal in coal/air mixture on mixture temperature. Comparison the calculated data with experimental one [13].

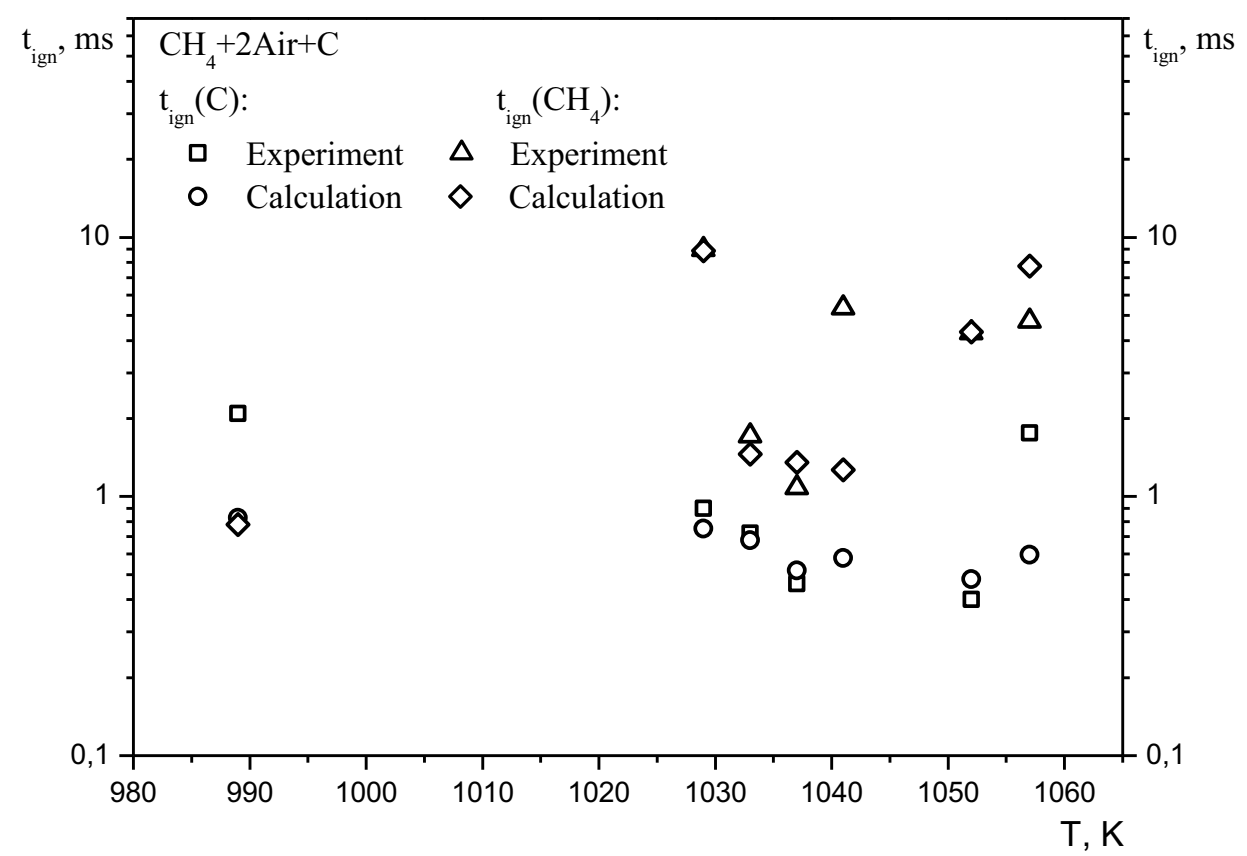

Fig. 2. Dependences of ignition delay times of methane and coal particles in methane/coal particles /air mixture on mixture temperature. Comparison of the calculated data with experimental one [13]. 


\section{Conclusions}

Physical and mathematical model of ignition and combustion of methane/air mixture in the presence of coal microparticles, which takes into account the detailed kinetics of oxidation of methane/hydrogen/air mixture and the thermal destruction of coal particles with the volatile (methane and hydrogen) release into the gas phase, ignition and combustion of volatile in the gas phase and the heterogeneous carbon oxidation reaction is proposed.

The calculated data of the ignition delay times of coal particles in the coal particles /air mixture and of the ignition delay times of methane and coal particles in the methane/coal particles/air mixture are compared with the experimental ones [13]. A satisfactory agreement of the data on the coal particles ignition delay times and methane ignition delay times in all considered mixtures is shown.

The work was supported by the Russian Foundation for Basic Research (grant No. 16-58-00052Bel_a).

\section{References}

1. V.I. Babiy, Yu.F. Kuvaev, Combustion of coal dust and calculation of a pulverized coal flare (Energoatomizdat, Moscow, 1986). [in Russian]

2. J. Nagy, D.W. Mitchell, Experimental coal-dust and gas explosions, Washington, U.S. Department of the Interior, Bureau of Mines, 1963)

3. P.R. Amyotte, K.J. Mintz, M.J. Pegg, Y.H. Sun, Fuel 72, 671 (1993)

4. A.V. Fedorov, Combust. Explos. Shock Waves 34, 418 (1998)

5. A.V. Fedorov, V.M. Fomin, Yu.A. Gosteev, Dynamics and ignition of gas suspensions (NSTU, Novosibirsk, 2006) [in Russian]

6. Yu.A. Gosteev, A.V. Fedorov, Combust. Explos. Shock Waves 37, 646 (2001)

7. Yu.V. Kazakov, A.V. Fedorov, V.M. Fomin, Archivum Combustionis. 7, 353 (1987)

8. A.V. Fedorov, T.A. Khmel, Combust. Explos. Shock Waves 38, 700 (2002)

9. C.K. Westbrook, P. Urtiew, Combust. Explos. Shock Waves 19, 65 (1983) [in Russian]

10. D.A. Tropin, A.V. Fedorov, Combust. Explos. Shock Waves 50, 542 (2014)

11. D.A. Tropin, A.V. Fedorov, O.G. Penyazkov, V.V. Leschevich, Combust. Explos. Shock Waves 50, 632 (2014)

12. A.V. Fedorov, D.A. Tropin, Combust. Explos. Shock Waves 44, 552 (2008)

13. V.V. Leschevich, O.G. Penyazkov, S.Yu. Shimchenko, Combust. Explos. 9, 3 (2016) 